\title{
Características mecânicas de concreto confeccionado com aregado miúdo artificial peneirado proveniente do calcário
}

Mechanical properties of concrete made with small artificial sifted aggregate coming from limestone

Propiedades mecánicas del hormigón fabricadas con pequeños agregados artificiales que provienen de la piedra caliza

José Vitor Ranieri Moreira Engenheiro Civil, UFMT, Brasil jvranierimoreira@gmail.com

Vitória Leventi Aleixes Kersting Roque Graduanda em Engenharia Civil, UFMT, Brasil vitorialeventi@hotmail.com 
RESUMO

Tendo em vista que a areia natural é um recurso não renovável e seu uso provoca problemas para a sociedade em função da degradação ambiental, o presente estudo tem como principal objetivo avaliar as características mecânicas quando há uso de agregado miúdo artificial peneirado proveniente do calcário no traço do concreto. Este artigo detalha os ensaios feitos com corpos de prova de concreto aos 28 dias e compara a eficiência mecânica entre o uso de areia natural e artificial na confecção destes. Estes ensaios são: resistência a compressão axial, resistência à tração diametral e o slump-test. O resultado obtido com os ensaios mostra que a substituição de agregado miúdo natural por esse material provoca uma diminuição da resistência à compressão axial e, também, da resistência à tração por compressão diametral, mas que pode ser usado na composição concreto.

PALAVRAS-CHAVE: Concreto. Areia artificial. Calcário.

\section{ABSTRACT}

Bearing in mind that the natural sand is a non-renewable resource and its usage causes problems for society because of environmental degradation, the present study has as main purpose to evaluate the mechanical properties when there's use of artificial small aggregate coming from limestone in concrete's trace. This article details the trials made with concrete specimens after 28 days and compares the mechanical eficience between natural and artificial sand usage. These trials are: resistance to axial compression, tensile strength by diametrical compression and the slump-test. The result obtained in the trials shows that the replacement of natural small aggregate for this material causes a reduction of axial compression resistance and, also, of tensile strength by diametrical compression resistance, but it can be used in concrete's composition.

KEYWORDS: Concrete. Artificial sand. Limestone.

\section{RESUMEN}

Teniendo en cuenta que la arena natural es un recurso no renovable y que su uso causa problemas a la sociedad debido a la degradación ambiental, el presente estudio tiene como objetivo principal evaluar las propiedades mecánicas cuando se utiliza agregado artificial artificial proveniente de la piedra caliza en el trazado del concreto . Este artículo detalla los ensayos realizados con muestras de concreto después de 28 días y compara la eficiencia mecánica entre el uso de arena natural y artificial. Estos ensayos son: resistencia a la compresión axial, resistencia a la tracción mediante compresión diametral y la prueba de asentamiento. El resultado obtenido en los ensayos muestra que la sustitución del agregado natural pequeño por este material provoca una reducción de la resistencia a la compresión axial y, también, de la resistencia a la tracción por la resistencia a la compresión diametral, pero puede usarse en la composición del hormigón.

PALABRAS CLAVE: Hormigón. Arena artificial. Piedra caliza. 


\section{INTRODUÇÃO}

A questão ambiental e sustentabilidade são assuntos muito discutidos atualmente e carregam consigo extrema importância para a perpetuação da qualidade de vida do homem no futuro. Dentro deste panorama encontra-se o setor da construção civil. Os desafios são complexos, pois é preciso que haja avanço na qualidade dos métodos construtivos e ao mesmo tempo buscar fazer uso de materiais reciclados e evitar ao máximo o uso de recursos naturais. Necessita-se de muita inovação no setor, para que a sustentabilidade, viabilidade técnica e segurança das edificações caminhem juntas.

O concreto é o material mais utilizado na construção civil no mundo. Em muitos países, o consumo de concreto é 10 vezes maior que o de aço. Em artigo publicado pela revista Concreto \& Construções (2009), cita-se que o consumo mundial de concreto fora estimado em onze bilhões de toneladas de concreto, ou seja, 1,9 tonelada por ser habitante. 0 homem não consome nenhum outro material em tal quantidade a não ser a água.

Vale ressaltar que, para produzi-lo, é necessário, além do cimento, a utilização de agregados graúdos e miúdos. Em relação ao agregado miúdo, a quantidade de areia consumida anualmente na construção civil brasileira é de 320 milhões de m3. Este volume daria para construir 7100 estádios como o Maracanã. Quase todo esse material é retirado das baixadas e dos leitos dos rios (MENOSSI, 2004).

Além disso, a areia natural é um recurso não renovável e ao ser extraída causa inúmeros impactos negativos no meio-ambiente, como o aumento da vazão de rios, aumento da velocidade do processo de erosão, esterilização dos solos, entre outros.

Por outro lado, estuda-se uma alternativa para substituir parcialmente ou totalmente o uso deste recurso de forma que aumente seu custo-benefício e amenize os impactos ambientais. Esta alternativa é a substituição da areia natural pela areia artificial, mais conhecida por pó de brita ou areia de brita. Nesse sentido, essa areia artificial é resultada da extração de calcário ou granito, por exemplo.

No cenário brasileiro, a utilização deste material ainda não é muito difundida na confecção de concreto e argamassa. Isso ocorre, provavelmente, pela falta de conhecimento técnico sobre o material e/ou pela alta disponibilidade do recurso natural.

Sendo assim, diante da potencialidade da utilização deste material vislumbra-se utilizá-lo na produção de concreto substituindo a areia natural. Para garantir sua viabilidade no meio técnico, será pesquisado um tipo de traço no qual a areia natural será substituída pela artificial provinda do calcário peneirado (passante na peneira 4,8mm) para caracterizá-lo. Foram avaliadas as seguintes propriedades mecânicas: resistência a compressão axial e resistência a tração por compressão diametral. Os ensaios foram realizados 28 dias após a moldagem dos corpos de prova. 


\section{ANAP Brasil \\ ISSN 1984-3240 \\ v. 10, n. 21}

\section{REVISTA CIENTIFICA 2017}

\section{OBJETIVO}

\subsection{Objetivo Geral}

O objetivo da pesquisa é verificar a viabilidade técnica da utilização da areia artificial para a produção de concreto em substituição a areia natural. Fazer uma comparação entre corpos de prova de concreto moldados com os seguintes agregados miúdos: areia natural, areia artificial peneirada (oriunda do calcário). Além disso, este trabalho busca a confecção de um concreto com areia artificial que tenha trabalhabilidade e relação água/cimento igual ao concreto com areia natural com auxílio de aditivos plastificantes.

\subsection{Objetivos Específicos}

a) Obter a curva granulométrica, módulo de finura e diâmetro máximo dos agregados miúdos e naturais;

b) Manter a relação água/cimento em 0,6;

c) Realizar o ensaio de compressão axial aos 28 dias de validade dos corpos de prova;

d) Realizar o ensaio de tração por compressão diametral aos 28 dias de validade dos corpos de prova.

\section{METOdOLOGIA}

\subsection{Materiais Componentes}

Para a confecção dos corpos de prova houve permuta entre areia artificial originária do calcário e areia natural. A primeira é proveniente de resíduos da produção da brita e fica armazenada nas pedreiras, sem que haja dada a elas uma destinação específica. Além destes materiais, usou-se água, cimento, agregado graúdo e aditivo plastificante na composição do concreto.

\subsubsection{Caracterização dos Agregados}

Agregado miúdo: com o material seco, foram separadas duas amostras de 1000 gramas de agregado de acordo com a ABNT NBR NM 248/2003. Os materiais passaram pelas peneiras da série normal $(4,80 \mathrm{~mm} ; 2,40 \mathrm{~mm} ; 1,20 \mathrm{~mm} ; 0,60 \mathrm{~mm} ; 0,30 \mathrm{~mm}$ e $0,15 \mathrm{~mm})$. Além destas peneiras, utilizaram-se peneiras da série intermediária $(0,85 \mathrm{~mm}$ e 0,43 $\mathrm{mm})$.

Agregado graúdo: com o material seco, foram separadas duas amostras de 5000 gramas de agregado de acordo com a ABNT NBR NM 248/2003. Os materiais passaram pelas peneiras da série normal $(25,00 \mathrm{~mm} ; 12,00 \mathrm{~mm} ; 6,00 \mathrm{~mm} ; 2,36 \mathrm{~mm} ; 1,20 \mathrm{~mm}$ e $0,60 \mathrm{~mm})$. Além destas peneiras, utilizaram-se peneiras da série intermediária $(19,00 \mathrm{~mm}$ e $9,50 \mathrm{~mm})$.

O material retido em cada peneira e o fundo (material que não ficou retido em nenhuma peneira) foi pesado. A porcentagem de material retido e a porcentagem acumulada em cada diâmetro de peneira foram determinadas. Com estes valores, conseguiu-se gerar as curvas 


\section{ANAP Brasil \\ ISSN 1984-3240 \\ v. 10, n. 21}

\section{REVISTA CIENTIFICA 2017}

granulométricas, diâmetro máximo e modulo de finura.

Diâmetro máximo está associado à distribuição granulométrica do agregado, e é o valor da abertura nominal (da série normal ou intermediária), em milímetros, em que a porcentagem retida acumulada é igual ou imediatamente inferior a 5,00\% em massa.

Módulo de finura corresponde à soma das porcentagens retidas acumuladas em massa do agregado, não é somado o valor das peneiras intermediárias. $O$ resultado é obtido através da divisão do somatório por 100.

\subsubsection{Areia Artificial Peneirada Originária do Calcário}

A areia artificial com origem do calcário tem pouca aplicação e quase não é comercializada. Devido ao fato deste material não receber tratamento na pedreira, foi realizado o ensaio de granulometria, buscando remover todo material com diâmetro maior que $4,80 \mathrm{~mm}$ e material com diâmetro menor que $0,15 \mathrm{~mm}$.

Com o ensaio granulométrico foi possível obter o módulo de finura igual a 3,34 e diâmetro máximo igual a 4,75 mm e a curva granulométrica é ilustrada na Figura 1.

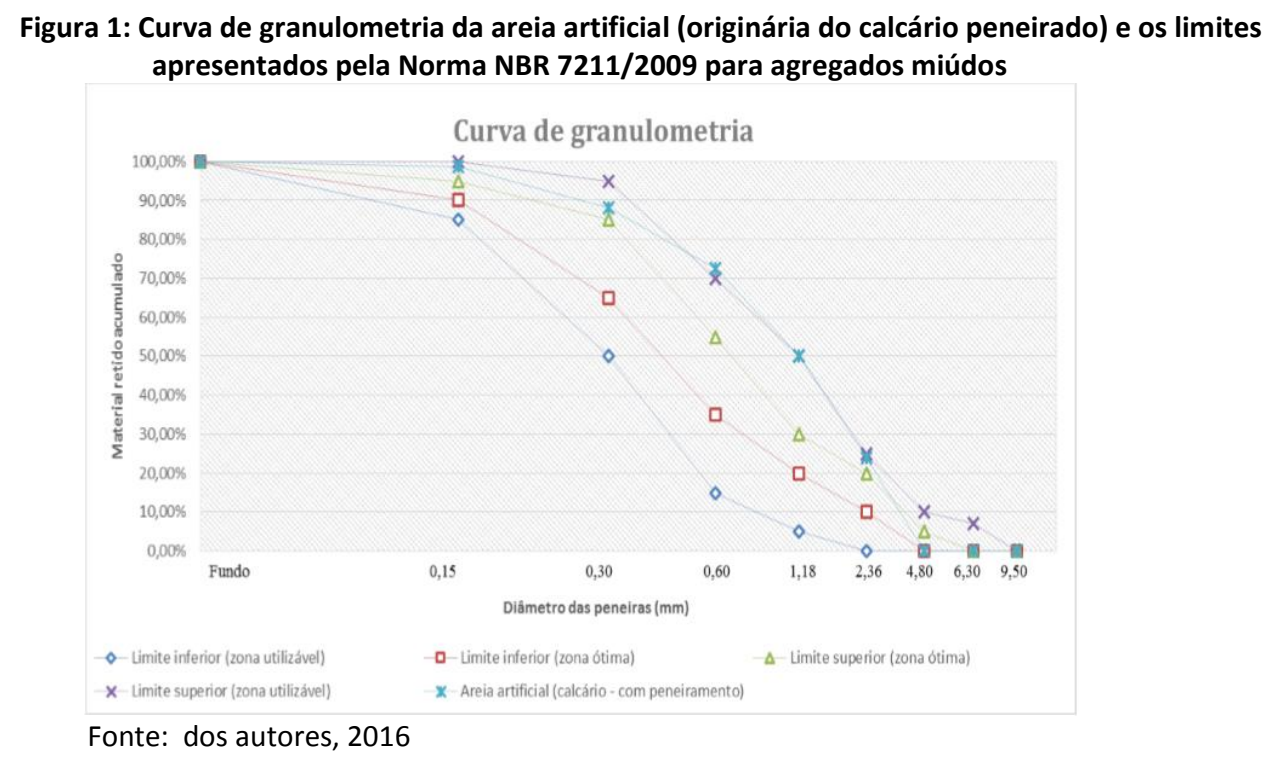

\subsubsection{Areia Natural}

A areia natural usada no trabalho é altamente comerciada na região de Cuiabá e cidades vizinhas. Este material é obtido do processo de extração no rio Cuiabá.

A areia natural apresentou diâmetro módulo de finura igual a 1,95 e diâmetro máximo igual a $6,3 \mathrm{~mm}$. A curva granulométrica obtida no ensaio de caracterização é ilustrada na Figura 2. 


\section{ANAP Brasil \\ ISSN 1984-3240 \\ v. 10, n. 21}

\section{REVISTA CIENTIFICA 2017}

Figura 02: Curva granulométrica da areia natural e os limites apresentados pela Norma NBR 7211/2009 para agregados miúdos

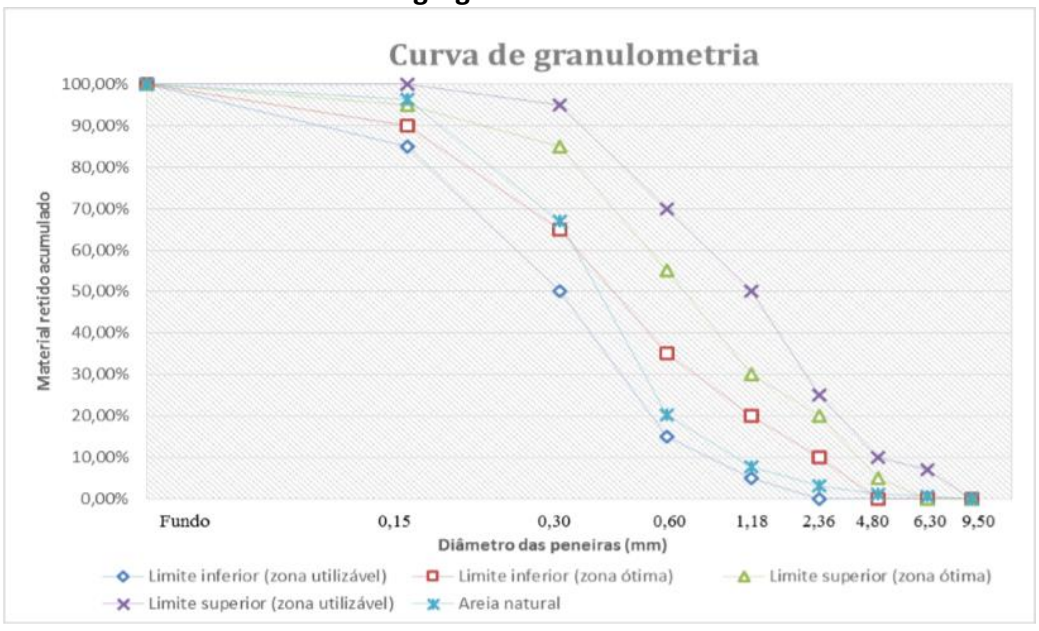

Fonte: dos autores, 2016

\subsubsection{Brita 01 (originária do calcário)}

A brita é extraída na região da Nossa Senhora da Guia - MT, município que se distancia 25 quilômetros de Cuiabá-MT.

A brita apresentou diâmetro máximo de $25 \mathrm{~mm}$ e o módulo de finura de 7,36. A curva granulométrica obtida no ensaio de caracterização é apresentada na Figura 3.

Figura 3: Limites apresentados pela Norma NBR 7211/2009 para agregados graúdos e curva de granulometria da brita 01 (originária do calcário)

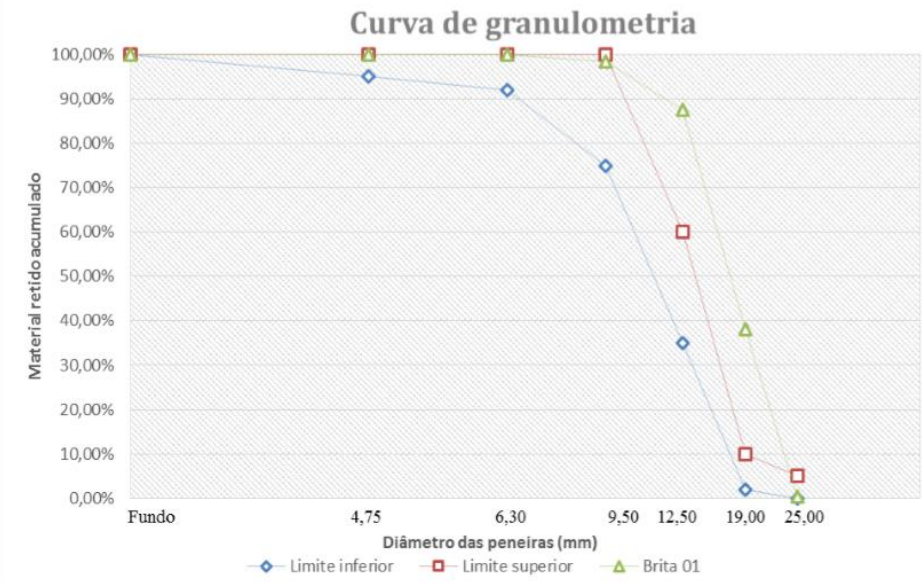

Fonte: dos autores, 2016

\subsubsection{Cimento}

O cimento Portland composto com Pozolana, CP II - Z 32 foi usado no desenvolvimento dos ensaios.

O cimento pode ter entre $6 \%$ e $14 \%$ de material pozolânico e apresentou massa específica média de $2,96 \mathrm{~g} / \mathrm{cm}^{3}$ (Norma NBR NM 23). 


\subsection{6. Água}

A água usada para execução dos concretos é fornecida pelo abastecimento da CAB Cuiabá na região do Coxipó, local onde foram realizados os ensaios.

\subsubsection{Aditivo}

Utilizaram-se dois aditivos para o desenvolvimento deste trabalho. 0 primeiro deles é o Sikament RM 300. É um aditivo líquido de pega normal, plastificante, capaz de reduzir quantidade de água para o concreto. Este foi usado na produção do concreto de areia natural. Já para produção do concreto com areia artificial, tanto originário do granito quanto do calcário, usou-se o aditivo Sika Viscocrete 5700. Este é um aditivo líquido de pega normal (3o geração), usado geralmente para CAD (concreto de alto desempenho) e CAA (concreto auto adensável).

\subsection{Definição do Traço de Concreto}

\subsubsection{Método de Dosagem do Concreto}

O método para a dosagem do concreto utilizado foi o EPUSP/IPT. Primeiramente, definiu-se a relação água/cimento em 0,6 . O método entende que a melhor proporção entre cimento e agregados é aquela que obter menor uso de água para obter abatimento requerido. Após o fator a/c, determinou-se que o valor do Slump-test (abatimento) seria $10 \mathrm{~cm}( \pm 2 \mathrm{~cm})$.

Optou-se em fazer o traço de 1,0/6,0 (cimento/ agregados miúdos mais agregados graúdos), pois o intuito foi comparar o uso dos agregados miúdos naturais versus artificiais oriundos do calcário. Definiu-se, para isso, usar um traço pobre $(1,0 / 6,0)$ a fim de comparar o comportamento das areias.

Após a definição dos itens citados, buscou-se determinar qual era o teor ideal de argamassa para o traço. Ou seja, determinar quanto de agregado miúdo e de agregado graúdo eram necessários para atender os parâmetros pré-estabelecidos.

Nesta etapa, foi preciso iniciar com o teor de argamassa em 50,0\%, e durante o ensaio analisou-se o comportamento do concreto. A preocupação era que quando o teor de argamassa estivesse abaixo do ideal, haveria vazios no concreto, o que acarretaria em redução da resistência mecânica. Caso o teor estivesse acima do ideal, isso acarretaria em desperdício de cimento, pois haveria sobra de argamassa.

A Tabela 01 foi utilizada para a determinação do traço. Ela foi moldada para massa de brita de $35 \mathrm{~kg}$, devido às limitações de volume de concreto que poderiam ser executados em uma única vez na betoneira. Através da Tabela 1, era possível determinar quanto de massa de areia e cimento deveriam ser acrescentados para obtenção do teor de argamassa desejado. 


\section{ANAP Brasil

\section{REVISTA CIENTIFICA 2017}

\begin{tabular}{|c|c|c|c|c|c|c|c|}
\hline \multirow{2}{*}{$\begin{array}{l}\text { Teor } \\
\text { argamassa }\end{array}$} & \multirow[t]{2}{*}{ de } & \multicolumn{3}{|c|}{ Traço (1:6) } & \multirow{2}{*}{$\begin{array}{l}\text { Massa de } \\
\text { cimento } \\
(\mathrm{kg})\end{array}$} & \multirow{2}{*}{$\begin{array}{l}\text { Massa } \\
\text { de areia } \\
(\mathrm{kg})\end{array}$} & \multirow{2}{*}{$\begin{array}{l}\text { Massa } \\
\text { de brita } \\
(\mathrm{kg})\end{array}$} \\
\hline & & $\mathrm{c}$ & $\mathrm{a}$ & $\mathrm{p}$ & & & \\
\hline $45,0 \%$ & & 1 & 2,15 & 3,85 & 9,09 & 19,55 & 35,00 \\
\hline $46,0 \%$ & & 1 & 2,22 & 3,78 & 9,26 & 20,56 & 35,00 \\
\hline $47,0 \%$ & & 1 & 2,29 & 3,71 & 9,43 & 21,60 & 35,00 \\
\hline $48,0 \%$ & & 1 & 2,36 & 3,64 & 9,62 & 22,69 & 35,00 \\
\hline $49,0 \%$ & & 1 & 2,43 & 3,57 & 9,80 & 23,82 & 35,00 \\
\hline $50,0 \%$ & & 1 & 2,5 & 3,5 & 10,00 & 25,00 & 35,00 \\
\hline $51,0 \%$ & & 1 & 2,57 & 3,43 & 10,20 & 26,22 & 35,00 \\
\hline $52,0 \%$ & & 1 & 2,64 & 3,36 & 10,42 & 27,50 & 35,00 \\
\hline $53,0 \%$ & & 1 & 2,71 & 3,29 & 10,64 & 28,83 & 35,00 \\
\hline $54,0 \%$ & & 1 & 2,78 & 3,22 & 10,87 & 30,22 & 35,00 \\
\hline $55,0 \%$ & & 1 & 2,85 & 3,15 & 11,11 & 31,67 & 35,00 \\
\hline $56,0 \%$ & & 1 & 2,92 & 3,08 & 11,36 & 33,18 & 35,00 \\
\hline $57,0 \%$ & & 1 & 2,99 & 3,01 & 11,63 & 34,77 & 35,00 \\
\hline
\end{tabular}

Fonte: dos autores, 2016

De acordo com o traço definido em 1,0/6,0 (cimento/agregados miúdos mais agregados graúdos), a massa de brita definida em $35 \mathrm{~kg}$ e com a porcentagem de argamassa, foi possível determinar os coeficientes de agregado miúdo e graúdo do traço. Após isso, determinou-se o quantitativo de cimento e a massa de areia para cada teor de argamassa.

\subsubsection{Concreto com Areia Natural}

Para produção do concreto com areia natural, inicialmente foram usados $35 \mathrm{~kg}$ de brita, $25 \mathrm{~kg}$ da areia natural, 6 I de água e $10 \mathrm{~kg}$ de cimento. $O$ traço inicial (em massa) ficou em: 1: 2,5: 3,5 (cimento/areia/brita). Usou-se, também, o aditivo Sikament RM 300, quantitativo de $50 \mathrm{ml}$. Após isso, fez-se o ensaio de slump-test (abatimento), e o valor encontrado foi de $16 \mathrm{~cm}$.

Resolveu-se mudar o teor de argamassa de $50,0 \%$ para $54 \%$, para isso, foi preciso adicionar mais $5 \mathrm{~kg}$ de areia, 0,832 $\mathrm{kg}$ de cimento e 0,5 I de água (para manter fator água/cimento em $0,6)$. Além disso, adicionou-se $25 \mathrm{ml}$ de aditivo.

Assim, o traço final ficou em 1: 2,77: 3,23 (cimento/areia/brita). A relação a/c ficou em 0,6. E o quantitativo de aditivo em $75 \mathrm{ml}$. Com isso, o slump-test (abatimento) obtido ficou em 10,5 $\mathrm{cm}$, assim atendendo o objetivo do trabalho.

\subsubsection{Concreto com Areia Artificial originária do Calcário com Peneiramento}

Para produção do concreto com areia artificial (originária do calcário com peneiramento), inicialmente foram usados $35 \mathrm{~kg}$ de brita, $30 \mathrm{~kg}$ da areia natural, 6,5 I de água e 10,832 kg de cimento. O traço inicial ficou em: 1: 2,77: 3,23 (cimento/areia/brita). Usou-se, também, o aditivo Sika Viscocrete 5700, quantitativo de $20 \mathrm{ml}$. Após isso, fez-se o ensaio de slump-test (abatimento), e o valor encontrado foi de $8 \mathrm{~cm}$. 


\section{ANAP Brasil}

ISSN 1984-3240

v. 10, n. 21

\section{REVISTA CIENTIFICA 2017}

Resolveu-se manter o teor de argamassa em $54 \%$ e adicionou-se $10 \mathrm{ml}$ de aditivo. Assim, o traço final ficou em 1: 2,77: 3,23 (cimento/areia/brita). A relação a/c ficou em 0,6. E o quantitativo de aditivo em $30 \mathrm{ml}$. Com isso, o slump-test (abatimento) obtido ficou em $9,5 \mathrm{~cm}$, assim atendendo o objetivo do trabalho.

\subsubsection{Traço do Concreto}

$\mathrm{Na}$ Tabela 2 são apresentadas as informações gerais, entre elas os traços de concreto utilizados para cada tipo de agregado miúdo utilizado na pesquisa. O quantitativo e o tipo de aditivo, a relação água/cimento, os teores de argamassa e os valores de slump-test.

\begin{tabular}{llllllllll}
\multicolumn{8}{c}{ Tabela 2: Resumo dos Concretos Moldados } \\
\hline Item & $\begin{array}{l}\text { Cimento } \\
(\mathrm{kg})\end{array}$ & $\begin{array}{l}\text { Areia } \\
(\mathrm{kg})\end{array}$ & $\begin{array}{l}\text { Brita } \\
(\mathrm{kg})\end{array}$ & $\begin{array}{l}\text { Argamassa } \\
(\text { teor })\end{array}$ & $\begin{array}{l}\text { Relação } \\
\mathrm{A} / \mathrm{C}\end{array}$ & $\begin{array}{l}\text { Aditivo } \\
(\mathrm{ml})\end{array}$ & $\begin{array}{l}\text { Aditivo } \\
(\mathrm{nome})\end{array}$ & $\begin{array}{l}\text { Slump- } \\
\text { teste }\end{array}$ \\
\hline $\begin{array}{l}\text { Concreto com areia } \\
\text { natural }\end{array}$ & 1,00 & 2,77 & 3,23 & $54,00 \%$ & 0,60 & 75,00 & $\begin{array}{c}\text { Sikament } \\
\mathrm{RM} 300\end{array}$ & 10,50 \\
\hline $\begin{array}{l}\text { Concreto com areia } \\
\text { artificial (originária } \\
\text { do calcário com } \\
\text { peneiramento) }\end{array}$ & 1,00 & 2,77 & 3,23 & $54,00 \%$ & 0,60 & 30,00 & $\begin{array}{c}\text { Siks } \\
\text { Viscococte } \\
5700\end{array}$ & 9,50 \\
\hline
\end{tabular}

Fonte: dos autores, 2016

\subsubsection{Massa específica}

Através da pesagem dos corpos de prova dos quatro tipos de concreto moldados e das dimensões dos corpos de prova, obtiveram-se os seguintes valores de massa específica: -Concreto com areia natural: $2377,4 \mathrm{~kg} / \mathrm{m}^{3}$;

-Concreto com areia artificial originária do calcário com peneiramento: $2430,1 \mathrm{~kg} / \mathrm{m}^{3}$.

\subsection{Ensaios Realizados}

Para a realização dos ensaios, foram moldados 20 corpos de prova que se dividem nos dois tipos de concreto. Além disso, para cada tipo de concreto, foram utilizados 12 corpos de prova para o ensaio de compressão axial e 8 corpos de prova para o ensaio de tração por compressão diametral.

\subsubsection{Moldagem dos Corpos de Prova}

Os corpos de prova foram moldados de acordo com a Norma NBR 5738/2015. Os corpos de prova cilíndricos apresentavam altura de $200 \mathrm{~mm}$ e diâmetro de $100 \mathrm{~mm}$. Os moldes eram de aço e antes de receberem o concreto foram revestidos com óleo mineral com intuito de facilitar a saída do corpo de prova do molde no momento da retirada do molde. A identificação foi feita com etiquetas. 


\section{REVISTA CIENTIFICA 2017}

Devido ao fato do adensamento ser manual, foram feitas duas camadas as quais receberam 12 golpes. Primeiramente, o concreto foi adicionado até altura em torno de $100 \mathrm{~mm}$ uniformemente distribuídos, após isso aplicado 12 golpes com a haste. Em um segundo momento, foi adicionado mais concreto ultrapassando, assim, o volume necessário que faltava para preencher o molde. Foram aplicados mais 12 golpes com a haste e fez-se o rasamento para remover concreto em excesso.

Os corpos de prova ficaram armazenados por 24 horas em um local protegido de intempéries e que evitasse ter vibração ou perda de água. Após esse período, os corpos de prova foram retirados do molde e foram colocados em tanques de água. Só foram retirados do tanque após 28 dias, ou seja, no dia dos ensaios.

Figura 04: Execução dos 12 golpes com a haste na primeira camada de um corpo de prova

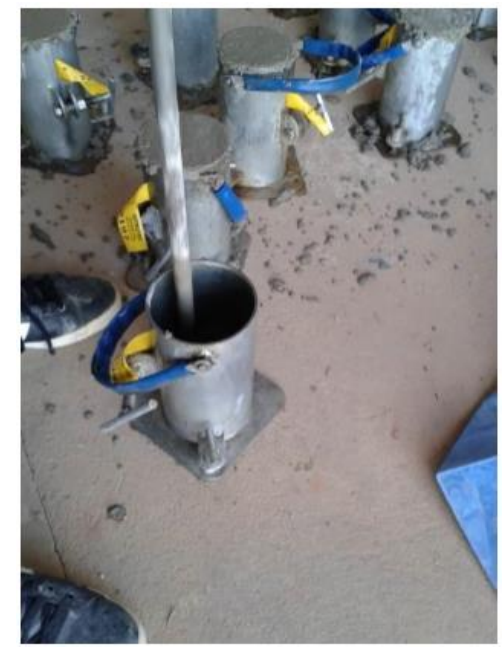

Fonte: dos autores, 2016 


\subsubsection{Ensaio do abatimento de tronco de cone (Slump-test)}

O ensaio do abatimento do tronco de cone foi realizado de acordo com Norma NBR NM 67 "Concreto - Determinação da consistência pelo abatimento do tronco de cone - Método de ensaio" (ABNT, 2003). Este método busca determinar a consistência do concreto.

Para a execução dos dois tipos de concreto, houve a realização do ensaio de abatimento do tronco de cone (slump-test) mais de uma única vez. Os ensaios foram realizados durante o processo de execução do concreto.

Para realização do ensaio usaram-se os seguintes materiais: haste, tronco de cone vazado, colher de pedreiro, tábua metálica, régua e água. Antes de começar o ensaio, umedeceu-se a tábua e o tronco de cone.

Primeiramente, o concreto foi adicionado até $1 / 3$ da altura do tronco de cone, foram executados 25 golpes com a haste uniformemente distribuídos na superfície com intuito de adensar o material. Após isso, adicionou-se concreto até a altura de $2 / 3$ e executados mais 25 golpes com a haste. Adicionou-se concreto em excesso que ultrapassasse o volume necessário para preenchimento do tronco de cone e foram aplicados mais 25 golpes.

Retirou-se o excesso de concreto da superfície do tronco de cone com a colher de pedreiro. $\mathrm{O}$ tronco de cone foi removido da placa, assim o concreto no seu interior tomou forma de tronco de cone. Após isso, mediu-se a altura do abatimento com uso de uma régua e da haste.

\subsubsection{Ensaios de compressão axial}

Os ensaios de compressão axial foram feitos segundo a Norma NBR 5739/2007. Até a data do ensaio (28 dias), todos os corpos de prova foram mantidos no processo de cura úmida.

Os corpos de prova cilíndricos apresentavam altura de $200 \mathrm{~mm}$ e diâmetro de $100 \mathrm{~mm}$. Estes foram limpos e secos antes de serem colocados na prensa para realização do ensaio. O corpo era centralizado na prensa no sentido longitudinal e a máquina apresentava o valor da força em toneladas. Além disso, a velocidade do ensaio se manteve constate em todos os corpos de prova. 


\section{ANAP Brasil \\ ISSN 1984-3240 \\ v. 10, n. 21}

\section{REVISTA CIENTIFICA 2017}

Figura 05: Corpo de prova após ruptura no ensaio de compressão axial

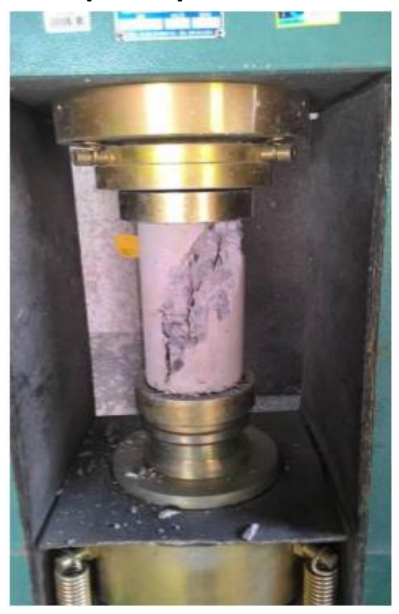

Fonte: dos autores, 2016

\subsection{4- Ensaio de tração por compressão diametral}

Os ensaios de tração por compressão diametral foram feitos segundo a Norma NBR $7222 / 2010$. Até a data do ensaio ( 28 dias), todos os corpos de prova foram mantidos no processo de cura úmida.

Os corpos de prova cilíndricos apresentavam altura de $200 \mathrm{~mm}$ e diâmetro de $100 \mathrm{~mm}$. Estes foram limpos e secos antes de serem colocados na prensa para realização do ensaio. $\mathrm{O}$ corpo era centralizado na prensa no sentido horizontal. A máquina apresentava o valor da força em toneladas e a velocidade do ensaio se manteve constate em todos os corpos de prova.

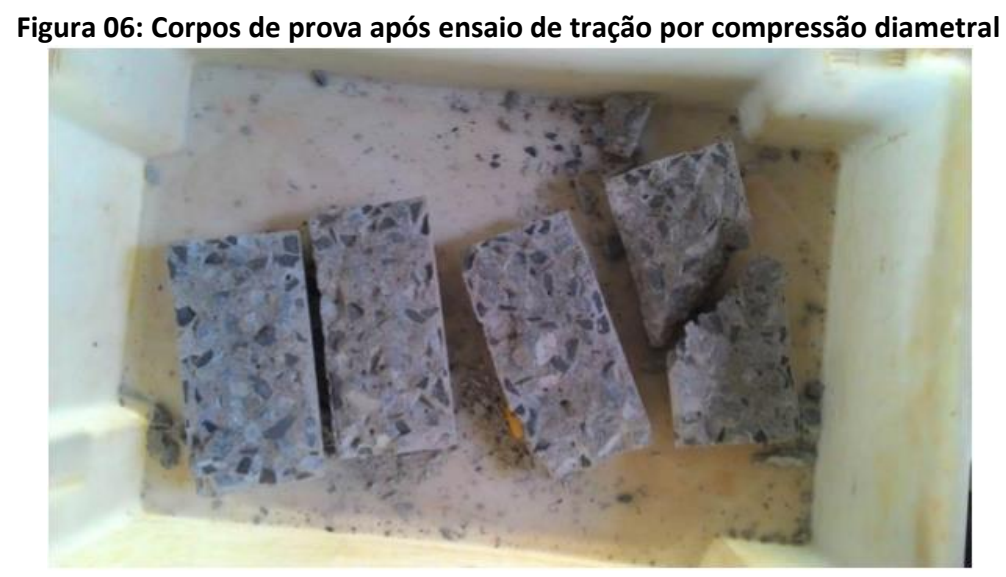

Fonte: dos autores, 2016 


\section{ANAP Brasil \\ ISSN 1984-3240 \\ v. 10, n. 21}

\section{REVISTA CIENTIFICA 2017}

\section{RESULTADOS}

Após a determinação do valor de resistência à compressão axial e de tração por compressão diametral dos lotes de corpos de prova, determinou-se o resultado médio de acordo com a Norma NBR 12655/2007 Concreto de cimento Portland - Preparo, controle e recebimento Procedimento.

A norma apresenta 05 diferentes casos para determinação do valor característico do concreto e o cálculo deste trabalho se baseou no item "6.2.3.1 Controle estatístico do concreto por amostragem parcial". E, também, para exemplares que estão no intervalo entre 6 e 20 corpos de prova. A fórmula para determinação do valor de resistência é:

$$
\text { Fckest }=\{[2 \times(f 1+f 2+\ldots+f m-1) /(m-1)]-f m\}
$$

Onde:

$\mathrm{n}$ : quantitativo de exemplares;

$m=n / 2$ : Despreza-se o valor mais alto de $n$, se for ímpar;

$f 1, f 2, \ldots, f m$ : valores das resistências dos exemplares, em ordem crescente.

Os exemplares foram constituídos por dois corpos de prova que foram moldados no mesmo ato, conforme diz a Norma NBR 5738/2015. Destes dois valores, tomou-se como resistência o maior dos valores obtidos para representar o exemplar, conforme é ilustrado na Tabela 3.

\begin{tabular}{|c|c|c|}
\hline & $\begin{array}{l}\text { Ensaio de } \\
\text { compressão axial }\end{array}$ & $\begin{array}{l}\text { Ensaio de tração por } \\
\text { compressão diametral }\end{array}$ \\
\hline $\begin{array}{l}\text { Concreto com areia } \\
\text { natural }\end{array}$ & $\begin{array}{c}6 \text { exemplares } \\
\text { compostos por } 2 \\
\text { CP's }\end{array}$ & $\begin{array}{c}4 \text { exemplares } \\
\text { compostos por } 2 \text { CP's }\end{array}$ \\
\hline $\begin{array}{l}\text { Concreto com areia } \\
\text { artificial (originária } \\
\text { do calcário, com } \\
\text { peneiramento) }\end{array}$ & $\begin{array}{c}6 \text { exemplares } \\
\text { compostos por } 2 \\
\text { CP's }\end{array}$ & $\begin{array}{c}4 \text { exemplares } \\
\text { compostos por } 2 \mathrm{CP} \text { 's }\end{array}$ \\
\hline
\end{tabular}

\subsection{Análise dos Resultados}

Os valores de compressão e tração foram calculados seguindo a Norma NBR 12655/2007 utilizando dados obtidos para cada corpo de prova testado nos ensaios de compressão axial e tração por compressão diametral. Esses valores são apresentados na Tabela 4. 


\section{ANAP Brasil \\ ISSN 1984-3240 \\ v. 10, n. 21}

\section{REVISTA CIENTIFICA 2017}

Tabela 4: Valores determinados a partir dos ensaios de Compressão Axial e Tração por Compressão Diametral

\begin{tabular}{ccc}
\hline & $\begin{array}{c}\text { Compressão } \\
\text { (MPa) }\end{array}$ & $\begin{array}{c}\text { Tração } \\
\text { (MPa) }\end{array}$ \\
\hline $\begin{array}{c}\text { Concreto com areia } \\
\text { natural }\end{array}$ & 32,88 & 3,30 \\
\hline $\begin{array}{c}\text { Concreto com areia } \\
\text { artificial (originária } \\
\text { do calcário, com } \\
\text { peneiramento) }\end{array}$ & 30,76 & 3,15 \\
\hline
\end{tabular}

Fonte: dos autores, 2016

Os resultados encontrados para resistência a tração por compressão diametral estão próximo dos valores de 10,00 \% dos resultados encontrados para resistência a compressão axial.

A resistência do concreto da areia artificial originária do calcário com peneiramento chegou a diminuir aproximadamente $2 \mathrm{MPa}$ em comparação ao concreto feito com areia natural.

O objetivo de manter a relação água/cimento foi alcançado, pois todos os corpos de prova foram moldados com a relação igual a 0,6 . O valor do abatimento pelo ensaio de tronco de cone foi atendido, pois o concreto moldado com areia natural apresentou abatimento de 10,5 $\mathrm{cm}$ e o de areia artificial originária do calcário peneirada obteve valor de $9,5 \mathrm{~cm}$. Todos estes dentro do intervalo pré-estabelecido (entre $8,0 \mathrm{~cm}$ e $12,0 \mathrm{~cm}$ ).

Para ambos os concretos moldados foram usados teores de argamassa igual ao valor de $54,00 \%$.

De acordo com os resultados apresentados, é possível que se conclua que o concreto moldado com areia artificial (originária do calcário, com peneiramento) apresentou queda de $6,45 \% \mathrm{da}$ resistência a compressão axial.

Do ponto de vista da tração por compressão diametral, o concreto moldado com areia artificial (originária do calcário, com peneiramento) apresentou queda de 4,6 \% em sua resistência.

\section{CONCLUSÃO}

Conseguiu-se obter todas as curvas granulométricas dos agregados, módulos de finura e o diâmetro máximo dos agregados. Todos os lotes foram moldados com a relação água/cimento em 0,6 . Os ensaios de resistência a tração por compressão diametral e compressão axial foram realizados com 28 dias de validade. A substituição do agregado miúdo natural por um agregado miúdo artificial nos mostrou que interfere diretamente na resistência a compressão axial e na resistência a tração por compressão diametral.

Além disso, a curva granulométrica da areia artificial (originária do calcário) não apresentou comportamento semelhante à curva granulométrica da areia natural. A curva granulométrica esteve próxima dos limites de agregados miúdos que a Norma NBR 7211/2009 estabelece. Essa diferença é responsável por interferir, também, nas propriedades mecânicas do concreto. A mudança do tipo de aditivo conseguiu manter uma trabalhabilidade do concreto quase que uniforme, quando comparado concreto com areia artificial versus concreto com areia natural, pois os valores de abatimento obtidos foram semelhantes. 


\section{ANAP Brasil \\ ISSN 1984-3240 \\ v. 10, n. 21}

\section{REVISTA CIENTIFICA 2017}

Com os resultados obtidos, percebe-se que é possível que haja a substituição da areia natural pela artificial e, sendo assim, que os resultados de resistência mecânica possam atender ao pré-estabelecido.

É preciso um estudo mais aprofundado quanto à interferência do formato dos grãos da areia artificial versus os grãos da areia natural na produção do concreto. Pois o formato da areia natural é semelhante ao de uma esfera. Enquanto que o formato da areia industrial é diferente, apresenta um formato laminar. Isso acarreta numa mudança de área específica e isso gera mudanças nas propriedades do concreto no estado fresco e endurecido.

Para que se possa fazer a substituição em $100,00 \%$ do agregado miúdo natural pelo agregado miúdo artificial é preciso que sejam feitos mais estudos sobre a variação da curva de granulometria destes materiais. E, além disso, avaliar se é economicamente viável, o uso de aditivos para melhorar o desempenho do concreto com areia artificial.

\section{REFERÊNCIAS BIBLIOGRÁFICAS}

ABNT (Associação Brasileira de Normas Técnicas). NBR NM 23 - Cimento Portland e Outros Materiais em Pó Determinação da Massa Especifica. Rio de janeiro, 2001.

ABNT (Associação Brasileira de Normas Técnicas). NBR NM 67 - Concreto Determinação da Consistência pelo Abatimento do Tronco de Cone. Rio de janeiro, 1998.

ABNT (Associação Brasileira de Normas Técnicas). NBR NM 248 - Agregados - Determinação da Composição Granulométrica. Rio de janeiro, 2003.

ABNT (Associação Brasileira de Normas Técnicas). NBR NM-ISO 3310-1 - Peneiras de Ensaio - Requisitos Técnicos e Verificação - Parte 1: Peneiras de Ensaio com tela de Tecido Metálico (ISO 3310-1, IDT). Rio de janeiro, 2010.

ABNT (Associação Brasileira de Normas Técnicas). NBR 5732 - Cimento Portland comum. Rio de Janeiro, 1991.

ABNT (Associação Brasileira de Normas Técnicas). NBR 5738 - Concreto - Procedimento para Moldagem e Cura de Corpos de Prova. Rio de janeiro, 2015.

ABNT (Associação Brasileira de Normas Técnicas). NBR 5739 - Concreto - Ensaio de Compressão de Corpos-deProva Cilíndricos. Rio de janeiro, 2007.

ABNT (Associação Brasileira de Normas Técnicas). NBR 7211 - Agregados para Concreto. Rio de Janeiro, 1983.

ABNT (Associação Brasileira de Normas Técnicas). NBR 7211/2009 - Agregados para concreto - Especificação. Rio de janeiro, 2009.

ABNT (Associação Brasileira de Normas Técnicas). NBR 7222 - Concreto e Argamassa - Determinação da Resistência à tração por Compressão Diametral de Corpos de Prova Cilíndricos. Rio de janeiro, 2011.

ABNT (Associação Brasileira de Normas Técnicas). NBR 11678 - Aditivos para concreto de cimento Portland. Rio de Janeiro, 1992.

ABNT (Associação Brasileira de Normas Técnicas). NBR 11768 - Aditivos Químicos para Concreto de Cimento Portland - Resquisitos. Rio de janeiro, 2011.

ALMEIDA, S. L. M.; LUZ, A. B. Manual de agregados para a construção civil. CETEM (Centro de Tecnologia Mineral). Rio de Janeiro, 2009. 


\section{REVISTA CIENTIFICA 2017}

ALMEIDA, S. L. M.; SAMPAIO, J. A. Obtenção de areia artificial com base em finos de pedreiras. Contribuição técnica elaborada para a Revista Areia e Brita. CETEM (Centro de Tecnologia Mineral). Rio de Janeiro, 2002.

ALMEIDA, S. L. M.; SILVA, V. S. Areia artificial: uma alternativa econômica e ambiental para o mercado nacional de agregados. Comunicação Técnica do II SUFFIB - Seminário: o uso da fração fina da britagem. CETEM (Centro de Tecnologia Mineral). Rio de Janeiro, 2005.

BAUER, Falcão L. A. Materiais de Construção Civil. Editora LTC (Livros técnicos e Científicos), volume 01, 5o edição. Rio de Janeiro, 2014.

BAUER, Falcão L. A. Materiais de Construção Civil. Editora LTC (Livros técnicos e Científicos), volume 02, 5o edição. Rio de Janeiro, 2004.

BUTTLER, A. M. Concreto com agregado graúdos reciclados de concreto - Influência da Idade de reciclagem nas propriedades dos agregados e concretos reciclados. Dissertação de Mestrado, Universidade Federal de São Carlos, São Carlos, 2003.

BASTOS, S. R. B. Uso da areia artificial basáltica em substituição parcial à areia fina para a produção de concretos convencionais. Dissertação de mestrado, Universidade Federal de Santa Catarina, Florianópolis, 2002.

DÍAZ, V. O. Método de dosagem de concreto de elevado desempenho; (tradução MSc Eng. Avelino Aparecido de Pádua Crepaldi) - São Paulo: Globo, 1998.

GUIMARÃES, J. E. P. A Cal - Fundamentos e Aplicações na Engenharia. Pini. 2o edição. São Paulo, 2002.

HELENE, P. R. L. A Manual de dosagem e controle do concreto. Pini. Brasília, 1993.

MEHTA, P. K. \& MONTEIRO, P. J. M. Concreto: Estrutura, Propriedades e Materiais. Pini. 1o edição. São Paulo, 1994.

MENOSSI, R. T., Utilização do pó de pedra basáltica em substituição à areia natural do concreto. Dissertação de Mestrado, - Universidade Estadual Paulista, Ilha Solteira, 2004. 